RESEARCH ARTICLE

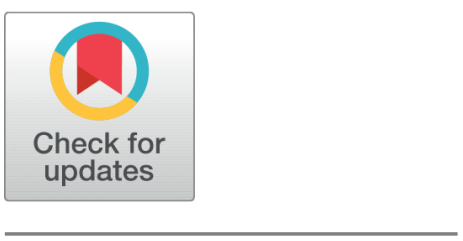

Open AcCess

Received: 01.07.2021

Accepted: 04.09.2021

Published: 03.10.2021

Citation: Haddad $\mathrm{H}$, Ono $\mathrm{H}$, Sarwari F (2021) The applicability of a non-motorized transportation system in the downtown of Baniyas city, Syria. Indian Journal of Science and Technology 14(32): 2626-2639. https://doi.org/

10.17485/IJST/v14i32.1229

* Corresponding author.

heba.haddad90b1h@gmail.com

Funding: None

Competing Interests: None

Copyright: ( 2021 Haddad et al. This is an open access article distributed under the terms of the Creative Commons Attribution License, which permits unrestricted use, distribution, and reproduction in any medium, provided the original author and source are credited.

Published By Indian Society for Education and Environment (iSee)

ISSN

Print: 0974-6846

Electronic: 0974-5645

\section{The applicability of a non-motorized transportation system in the downtown of Baniyas city, Syria}

\author{
Heba Haddad ${ }^{1 *}$, Hiroko Ono ${ }^{2}$, Fakhrullah Sarwari ${ }^{1}$ \\ 1 Graduate student, Faculty of civil engineering and architecture, University of the Ryukyus, \\ Okinawa, Japan \\ 2 Professor, Faculty of civil engineering and architecture, University of the Ryukyus, Okinawa, \\ Japan
}

\section{Abstract}

Objectives: This study aims to highlight the difficulties caused by the motorized transport system in the downtown of Baniyas city, Syria, and analyse the applicability of a non-motorized transport system based on a deep understanding of the nature of the society and the needs of the users. Methods: this study used the observation of the author and data obtained from official reports to identify the challenges in the downtown area caused by the current traffic system, a new non-motorized transport system was designed and proposed to the users through an online questionnaire using Qualtrics online survey tool. After the pilot sample testing the questionnaire was distributed to the targeted group of 326 participants with (11 invalid responses, 17 unqualified respondents and 298 valid responses). The data from their responses was exported to SPSS statistical analysis software then the qualitative data was analysed using SPSS and MS Excel. Findings: The most profound of the results is the significance of the relationship between the social reasons as a factor to prevent people from cycling and the variables of age and gender. The participants' level of being affected by social reasons varied depending on their age and gender. And when giving people the opportunity to cycle in better conditions after implementing the proposal, it was also found that the participants were positive towards the idea of riding the bicycle regardless of their gender, but according to their age, people reacted differently, the younger people had a positive opinion, but the relatively older people were neutral towards it. Novelty: It is being the first study to target the downtown of Baniyas city, and designs an approach to improve it in addition to design the non-motorized transport system questionnaire which was an original work of this study.

Keywords: Nonmotorized transport; Chi square test; Bicycling; Pedestrianization; New transportation system questionnaire 


\section{Introduction}

When the current methods of transport create an obstacle in the city's urban life and development and make the daily life of residents difficult, looking for new solutions becomes a basic stage to support the urban structure of the city and the life of its residents. The experience of completely banning vehicles within the city's centre and focusing on pedestrian and bicycle traffic (non-motorized) with great priority given to public spaces has proven to be a great success in many countries around the world. ${ }^{(1-3)}$ And since transportation is a main part of people's daily life, any intervention should be built on a deep understanding of the nature of the society and the user's needs. The increasing complications caused by motorized traffic and specially the traffic congestion within the cities and particularly in the downtown areas are day by day creating a bigger obstacle towards the urban development of the city and causing many social, economic, health and environmental problems. ${ }^{(4,5)}$ Because of these problems, non-motorized transport (pedestrian and bicycle) appears as an effective solution with many physical, socioeconomic, and environmental benefits. ${ }^{(6-8)}$

This study targeted the downtown area of Baniyas city- Syria, investigated the current issues related to transportation and examined the ability to solve these issues by implementing a non-motorized transport system in the downtown area while considering the nature of the society and the user's and their needs through conducting an online questionnaire.

\section{Methodology}

This study analysed the current situation of the traffic system in the downtown area of Baniyas city and its effects on pedestrians, car and public transport users using the observation of the author and data obtained from official studies, a new transportation system based on the non-motorized traffic was designed and proposed to the users through an online new transportation system questionnaire.

The questionnaire was designed by Qualtrics online survey tool, and the link was distributed to 32 users to analyse the reliability of the questions before distributing the questionnaire to the target group (over 320 people of a total population of 195000 for the city and its villages, the confident level $95 \%$ and the margin of error is 5\%).

Data from a pilot sample of 32 responders was collected via Qualtrics survey tool and exported to SPSS software and a pilot sample reliability test was conducted using Cronbach's alpha analysis method to check the reliability and internal consistency of the questions.

After testing the reliability, the questionnaire was distributed on the whole targeted group and the data of 326 participants with (11 invalid responses, 17 unqualified respondents and 298 valid responses), was collected through an online questionnaire using Qualtrics online survey tool and exported to SPSS statistical analysis software then the qualitative data was analysed using SPSS and MS Excel.

\section{Problem Identification}

\subsection{Delimitation of the study area}

Baniyas is a Syrian coastal city located on a small bay on the Mediterranean Sea at a height of 5 to 10 meters above sea level, and it follows the province of Tartous. Baniyas region is the largest area of the province of Tartous, with a total area of $588.7 \mathrm{~km} 2$ and a Population of 195000. ${ }^{(9)}$ Baniyas area consists of 7 districts and each district includes several cities, villages, and farms. The major district is Baniyas and Baniyas city is the main part of it. ${ }^{(10)}$

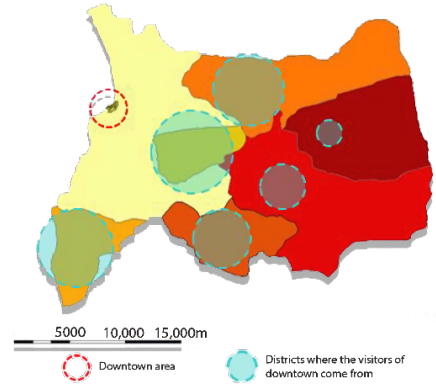

Fig 1. Location of the Main area of study in addition to other Districts where visitors of Downtown area come from ((Own elaboration, based on the report published by the transportation department of Tartus province) ${ }^{(11)}$ 
The area of study is the downtown Area of Baniyas city. And the research will cover two areas inside and outside the study area to ensure the impact of neighbouring areas.

\subsection{Mobility situation}

\subsubsection{Land use and type of activities}

Travel itself is a derived demand and it happens as a response to the type of activities within a certain area and knowing the type of land uses and activities within the area is important to understand the purposes of the trips.

Based on the purpose of the trips and according to a report by the department of city planning, Baniyas city office 2010 there are four main types of land uses in the study area (mixed use, public services, educational and historical ${ }^{(12)}$ (shown in Figure 2 )

As shown in Figure 2, the official land use of the study area is mostly one single type for most of the downtown area which is Mixed use and to understand the actual different uses within the first-floor level an observation study was conducted by walking in every street of the study area to register the actual types of uses. The current uses are divided into Markets with one specialty (commercial or industrial), retail shops, educational and service buildings. The annotations were marked on the street, instead of inside the blocks, because this study focuses on the public spaces, so the focus was to identify the types of activities that can be found when walking through the zone. (Shown in Figure 3). This is helpful to understand what happens in the downtown area, why people need to visit it, and provide information to make decisions to propose improvements on the public space of the study area. ${ }^{(13)}$

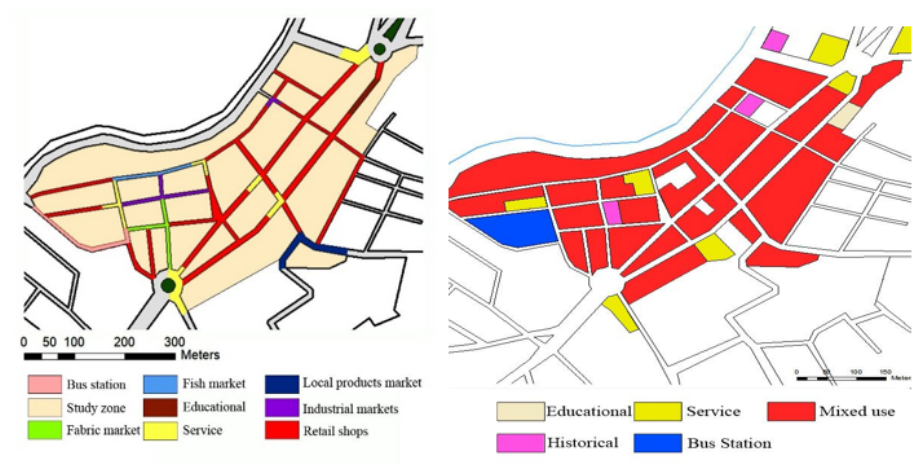

Fig 2. Map of the current state of the area of study and its surroundings. Own Elaboration: Data obtained from Baniyas city office, Department of City planning

\subsubsection{Observation of the Mobility situation}

In the next table, the observed mobility situation was described with a photo record,

Table 1. Photo recoding of the mobility situation in the study area, Taken by the author

\begin{tabular}{|c|c|c|c|}
\hline $\begin{array}{l}\text { The Mobility Fac- } \\
\text { tor }\end{array}$ & Public transportation & Street facilities for automobiles & challenges for Pedestrians \\
\hline Observed points & $\begin{array}{l}\text {-The minibus system is the only } \\
\text { transport system for the whole } \\
\text { city } \\
\text {-This system is not supported } \\
\text { by the public sector or any } \\
\text { organized private sector. } \\
\text { _Composed of a group of } \\
\text { minibuses operating on different } \\
\text { routes within the city. } \\
\text { _These minibuses do not have } \\
\text { specific stops within the city. } \\
\text { _No specific timetable. }\end{array}$ & $\begin{array}{l}\text { Due to the inappropriate situation of public } \\
\text { transportation, many people who need to } \\
\text { travel to the downtown area on daily basis } \\
\text { must use their own car. } \\
\text { - No suitable parking spots for cars, they } \\
\text { will park randomly near the sidewalk, } \\
\text { decreasing in street width } \\
\text {-No traffic light to organize the traffic } \\
\text { movement and limit the traffic accidents } \\
\text { especially in the high-risk intersections. }\end{array}$ & $\begin{array}{l}\text { _The narrow sidewalks, } \\
\text { _Sidewalks with poor condi- } \\
\text { tions } \\
\text { _Obstacles like poles, merchan- } \\
\text { dise, people waiting for the bus } \\
\text { without enough space, trees, } \\
\text { and parked automobiles. These } \\
\text { factors specifically affect the } \\
\text { blind and disable people } \\
\text { _The lack of pedestrian crossing } \\
\text { areas. } \\
\text { _lack of ramps }\end{array}$ \\
\hline
\end{tabular}




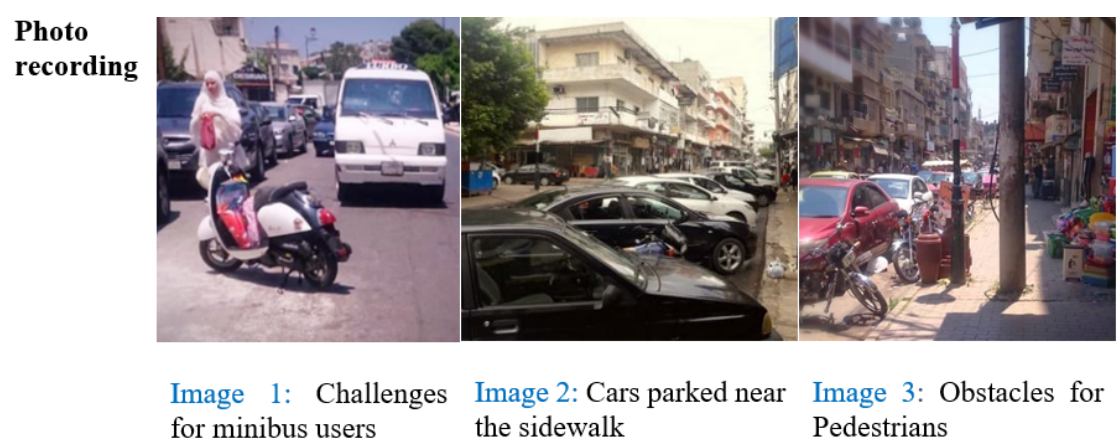

Fig 3. The Activities within the downtown area, Own elaboration, Based on the observation

\subsection{Discussion of the current mobility situation and its effects}

The types of land use and activities within the downtown area in addition to the existing situation of the motorized transportation are collaborating to create the traffic difficulties and congestion due to following reasons:

Reasons related to the type of activities_travel is directly connected to the types of land uses and activities located in a certain area and most of the important activities of Baniyas area are located within the downtown area, trips to achieve these activities have several intersections at the level of time duration. The downtown area is not only used as a shopping street or for public services, but it also contains the industrial markets and the local markets. Many people are trying to accomplish their purpose of visit at the same time, with no organized public transport service and routes, and unsuitable street facilities i.e., car parking. As a result, the downtown area will suffer from a severe traffic jam during the intersection periods of the different trips while the surroundings are almost empty.

Transport service situation _ the minibus service has no proper stops, as a result the minibuses will repeatedly stop for seconds to pick up or drop off passengers. This will cause a traffic shock wave.

Public transport routes_ most of the bus routes (trips for inside and outside the city) are passing through the downtown main streets instead of using another nearby street. This causes a high volume of traffic attempting to pass through the main downtown area specially within the peak time.

Reasons related to the car and pedestrian street infrastructure _ due to the unavailability of suitable parking spots for cars, they will be parked randomly near the sidewalks, decreasing in street width and highly contributing to the traffic jam situation .The unavailability of traffic lights and pedestrian crossing area will create a random traffic movement , as a result cars and pedestrian will cross the street randomly and whenever they find a chance, this will not only contribute to the traffic jam but also to the increasing of the rate of traffic accidents

\section{The applicability of the non-motorized system}

The main objective of the proposal is to promote the non-motorized automobile transport modes within the downtown area, starting from measuring the feasibility of the proposal from a technical point of view.

Knowing that the proper distance for the initial trips is about 15 minutes of travel time, equivalent to around $1 \mathrm{~km}$ walking $4 \mathrm{~km}$ by bicycle ${ }^{(15)}$ and when considering the centre of downtown area as starting point most of the city's neighbourhoods are accessible by walking and cycling. The factors climate conditions and the geographical feature of the city are some of the factors that may interfere to change the effectiveness of these radiuses ${ }^{(16)}$

The pedestrians and cyclists are highly affected by temperature, and this factor affects the trips distance on two levels : level of days and level of hours, the travel distance that pedestrians are willing to take will be decreased in hot days ,especially in the afternoon when the sun is very strong and the temperature is very high, and probably during same days it would be possible to travel longer distances early in the morning or after sunset, when temperature is more pleasant. Baniyas is a city with a dry Mediterranean climate in summer, rainy in winter ${ }^{(2,17)}$, a relatively high temperature is registered in June, July, August, and September the summer months with a moderate temperature throughout the year. Rain is another weather condition that affects the travel distance, and within Baniyas city the highest rate of precipitation occurs mainly in the months of winter (December, January, and February), and partially during some months of autumn and spring (March, October, and November) while summer is dry. ${ }^{(17)}$ 
Regarding the geographical features of the city, Baniyas is in the coastal plain between the Mediterranean Sea from the west and the coastal mountains from the east and this plain continues to narrow and widen from time to time between the mountains and the Mediterranean Sea. And this geographical feature gives a great opportunity for easy and convenient trips by walking (for short distances) and cycling from the downtown to most of the neighbourhoods of the city. Noticing that by considering the geography factor, the surrounding villages will be excluded from this possibility since all these villages (except Harrison village) are in mountainous areas.

Conclusion _ The current land uses, the type of activities and the mobility situation cause many challenges for the users and changes need to be made to enhance the functionality of the area of study. While considering the applicability of the nonmotorized proposal in the area, it is also important to consider the factors that can affect the feasibility of the non-motorized system such as weather conditions and provide a comfortable, safe, and attractive experience for the pedestrians (walking and cycling).

\section{The research instrument}

\subsection{The process of designing the survey of the new transport system}

It is very important to measure the public's acceptance of the new ideas and surveys are important tools for data collection to address different transportation planning issues. ${ }^{(18)}$

Transport surveys have several purposes, either alone or in combination, such as describing the existing condition at a given timeline, obtaining a greater understanding of the transport system behaviour, predicting the effect of the transport system changes, measuring the effects of system changes by conducting before and after surveys ${ }^{(19)}$. All details related to characteristic of our case study, the process of designing the questionnaire and the ways to present it to the target sample must be considered

The survey process can fail to achieve its purpose if it is not accompanied with a deep understanding of the distinguish and characteristics of each case study.

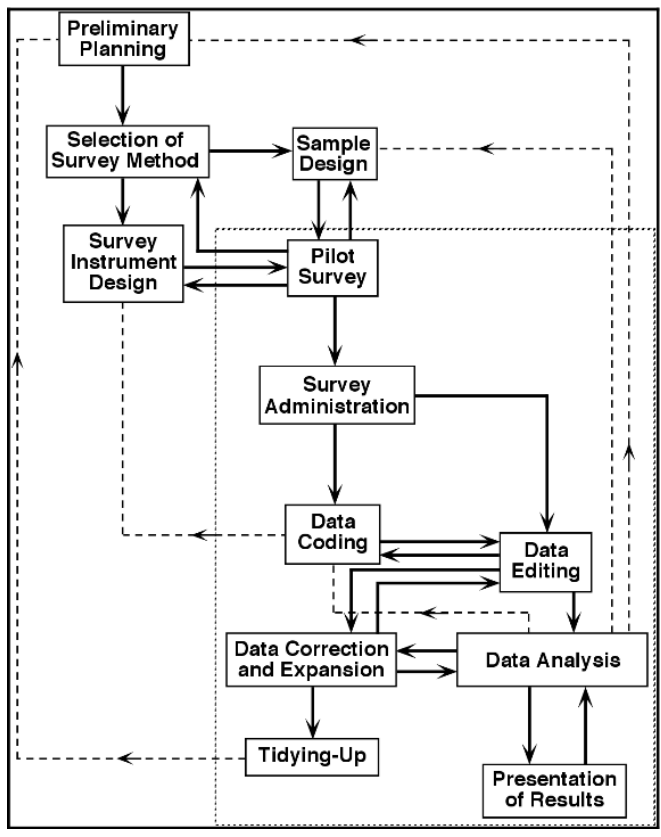

Fig 4. The transportation survey process. Source: Richardson et al.,1995

In the cases of transport system development, the users mostly do not have the required knowledge about our proposal, in most of the cases we are presenting entirely new ideas.

As a result of their lack of knowledge we cannot rely on their responses. Many literatures have dealt with this topic, and how the design of the questionnaire should be modified to grasp more reliable data from users and as a result it was confirmed that the media system explanation method with image was able to better explain and get more responses from the users". (20) The new transport system questionnaire was designed by presenting the new system explanation using a with-image media method 
to introduce the users to our new proposal to achieve the highest possible reliable response rate.

\subsection{The adopted methodology in designing the questionnaire}

The purpose of the questionnaire was explained at the introduction and the users were asked to read the explanation carefully before answering the question.

In the second part, the Advantages of this proposal were explained to the users with before and after images designed by the author using Autodesk Revit and Adobe Photoshop, these images explain the future vision of the downtown area, with before and after comparison to illustrate the proposed changes. (Shown in Figure 5 and Table 2)

Third part of the questionnaire was a special explanation targeted shop owners and car users about locations for car parking and the process of delivering the goods to the stores since the process of providing the stores within the downtown area with their goods after banning the automobile traffic within the area is one of the important points to be considered, the study proposed to allow the service trucks to access the downtown area during certain hours of the day.

And to find the best time for this procedure data were collected by interviewing 29 store owners from different specialities (electronic stores, clothing stores, pharmacies, grocery, and vegetables) about the current hours to receive their goods. And based on their responses the service process was explained in the questionnaire according to Table 3.

Table 2. The proposed process of delivering the goods

Access hours of the service trucks to provide the stores with their From 5PM until 7AM goods

$\begin{array}{ll}\text { The proposed lane for the service trucks } & \text { The service trucks will use the same pedestrian lane during their }\end{array}$ special hours

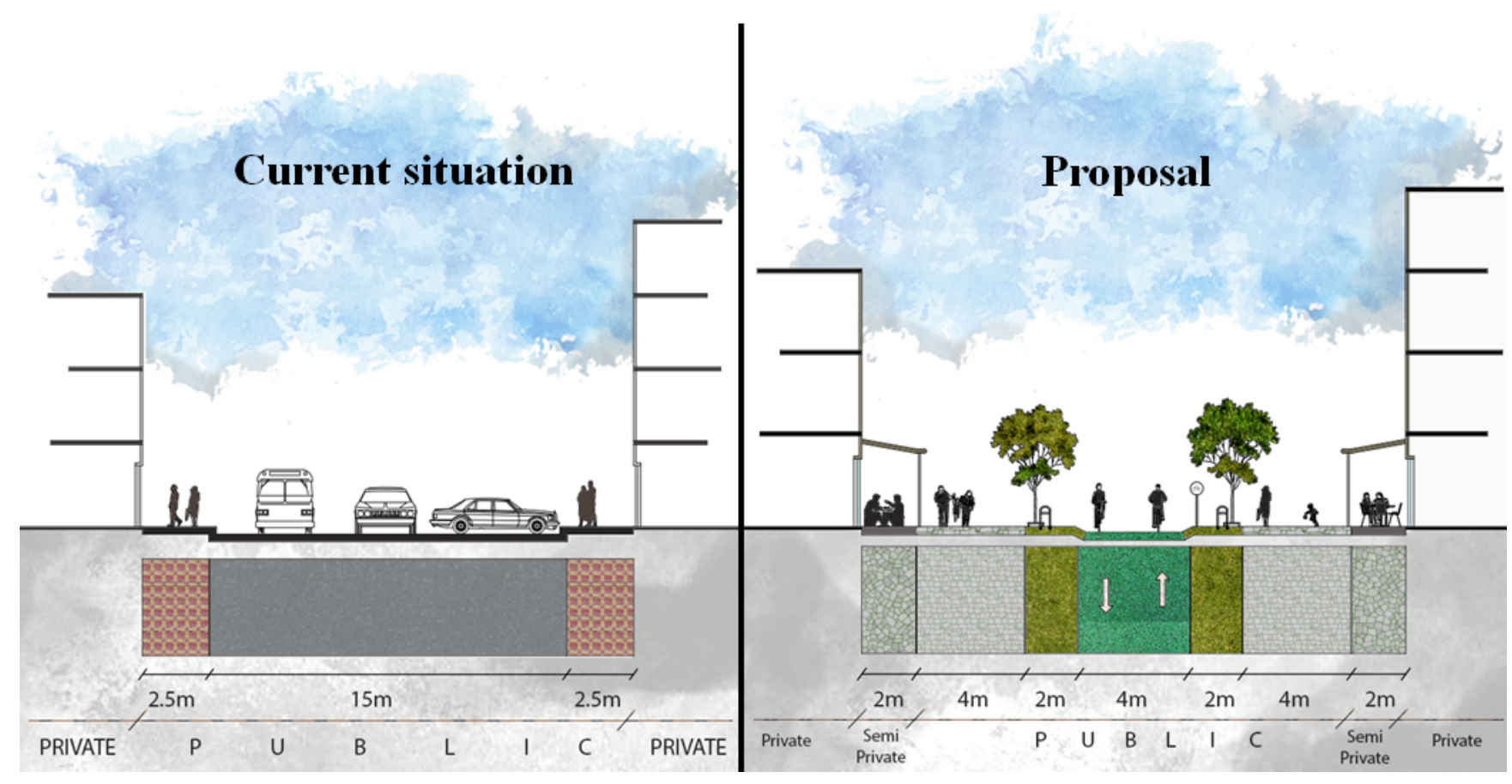

Fig 5. Comparison of the public and private space distributions 


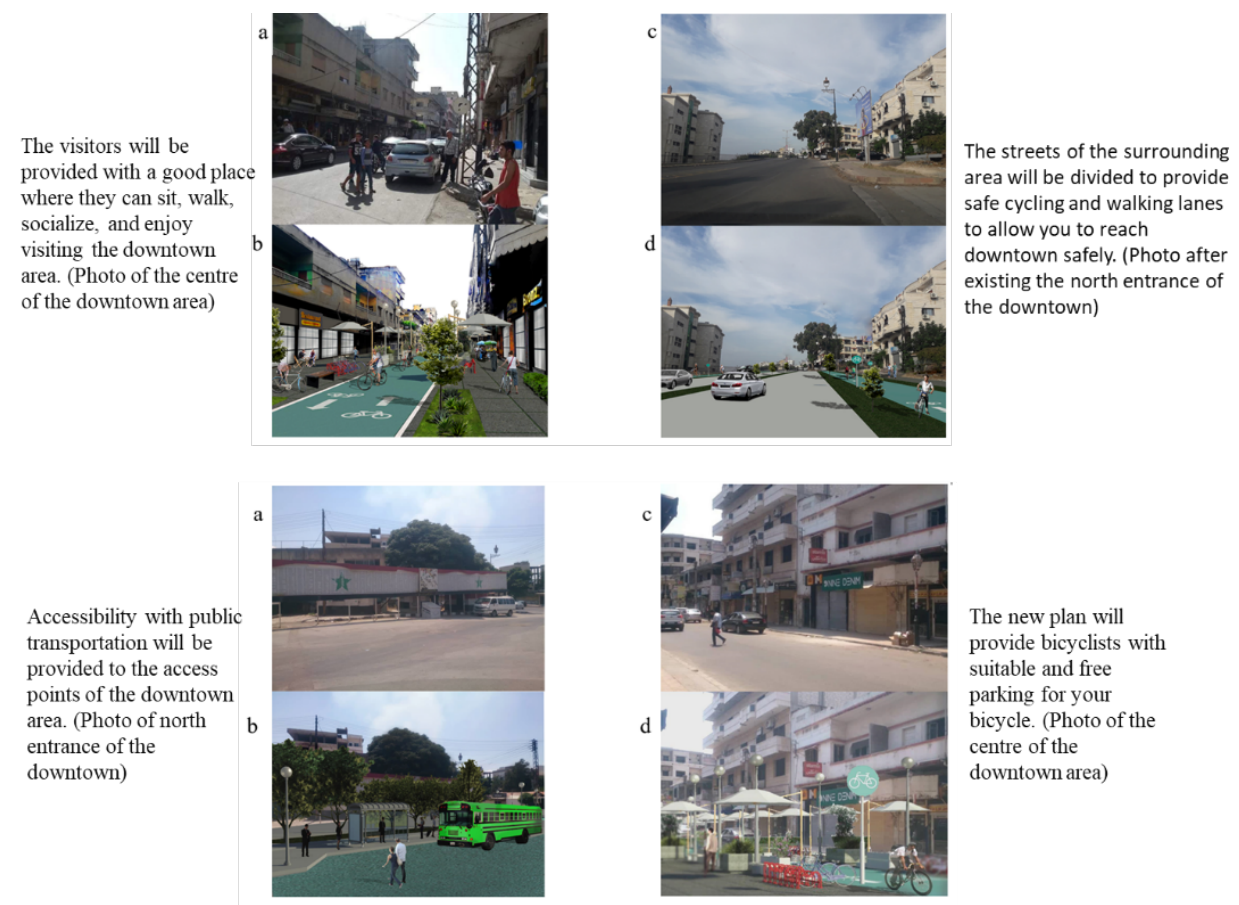

Illustration 1. Illustrating the proposed changes with before and after comparison

\subsection{The type of questions}

The questions were divided into 4 main categories: Socio demographic, Current choices of transport, User satisfaction of current mode of transportation and the ability to change the current mode of transportation. With a total number of 18 questions, a combination of multiple-choice questions, Likert scale and text entry questions were used. The participants were given a choice to add their suggestions and own point of view to some parts of the questionnaire

\subsection{Pilot testing}

Testing the length of the questionnaire (the time required to answer the questionnaire) As confirmed in many literatures a Pilot test is needed to ensure taking the test would take no more than $\frac{1}{2}$ hour. ${ }^{(21)}$ The shorter the length the better, especially if there are open-ended questions.

After checking the answer time duration recorded by Qualtrics survey tool for the 32 participants, focusing on the people who answered all the open-ended questions, the maximum time duration did not exceed 23 minutes.

Reliability of the research instrument _Cronbach's Alpha measures the internal consistency between items in a scale. Cronbach's Alpha reliability coefficient normally ranges between 0 and 1 with higher values indicating higher reliability among the indicators ${ }^{(22)}$ This means that the closer Cronbach's alpha coefficient is to 1.0 the greater the internal consistency of the items in the scale. If our analysis included less than 10 items $>0.5$, More than 10 items $>=0.7^{(23)}$

Within this test the data obtained from the pilot study of 32 participants from different groups (age, employment, vehicle ownership, location of resident) was examined to determine the validity and reliability of the instrument. The reliability test targeted the two groups of Likert scale questions (User satisfaction of current mode of transportation_ The ability to change the current mode of transportation) and the data was tested using SPSS statistic software.

For the first group (the user satisfaction of current mode of transportation)

Cronbach's alpha $=0.64>0.5=$ acceptable result

For the second group (The ability to change the current mode of transportation)

Cronbach's alpha $=0.8>0.5=$ acceptable result

As a result of this test, Alpha value indicates that our instrument is reliable, and we can distribute the questionnaire to the whole target group 


\section{The survey's Results and discussion}

The data of 326 participants with (11 invalid responses, 17 unqualified respondents and 298 valid responses), was collected through an online questionnaire using Qualtrics online survey tool and exported to SPSS statistical analysis software then the qualitative data was analysed using SPSS and MS excel. And a skip logic was added to the first question of the questionnaire, its purpose was to automatically ignore unqualified participants (people who are not related to the area of study), the remaining valid data represents the answers of 298 participants.

\subsection{Descriptive statistics}

Table 3. Demographics results

\begin{tabular}{|c|c|c|c|c|c|}
\hline Variable & Frequency & Percent & Variable & Frequency & Percent \\
\hline Gender: & & & Age: & & \\
\hline Male & 151 & $51 \%$ & Under 18 & 34 & $11 \%$ \\
\hline Female & 147 & $49 \%$ & Between 18 and 23 & 39 & $13 \%$ \\
\hline \multirow[t]{4}{*}{ Total } & 298 & $100 \%$ & Between 24 and 35 & 110 & $37 \%$ \\
\hline & & & Between 36 and 65 & 72 & $24 \%$ \\
\hline & & & Over 65 & 43 & $14 \%$ \\
\hline & & & Total & 298 & $100 \%$ \\
\hline Occupation: & & & Location: & & \\
\hline Self-employee & 48 & $16 \%$ & Within and nearby the downtown & 118 & $37.4 \%$ \\
\hline Public sector Employee & 74 & $25 \%$ & Other neighbourhoods & 115 & $36.5 \%$ \\
\hline Housewife & 21 & $7 \%$ & Neighbouring villages & 39 & $12.4 \%$ \\
\hline Student & 89 & $30 \%$ & Neighbouring cities & 26 & $8.3 \%$ \\
\hline Shop owner /workers & 60 & $20 \%$ & Unqualified participant & 17 & $5.4 \%$ \\
\hline Other & 6 & $2 \%$ & Total & 315 & $100 \%$ \\
\hline Total & 298 & $100 \%$ & & & \\
\hline
\end{tabular}

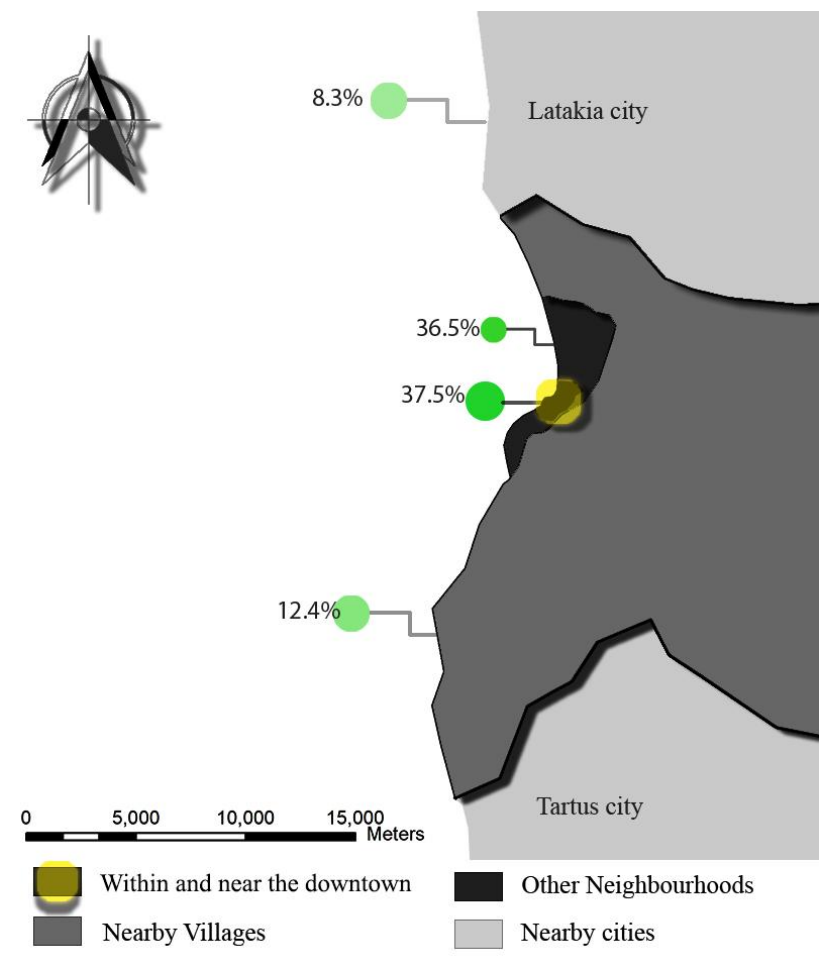

Fig 6. Participant's residence location 
The table shows the demographic distribution of the participants, after excluding the unqualified respondents. Within the valid responses there are $51 \%$ males and $49 \%$ females, $61 \%$ of the participants' age falls between 24 and 65 which makes them active and old enough to make good decisions regarding the methods of transportation. The occupation distribution of the respondents shows that all the main groups of occupation are generally well presented, with the ability to reach the group of shop owners and get their participation with $20 \%$ of the total percentage. while the other important groups as students were represented with $30 \%$, and $25 \%$ for the group of public sector employees. Data about the location of the participants shows that $37.46 \%$ of the participants live within the downtown area and nearby neighbourhoods, $36.51 \%$ live in other neighbourhoods inside Baniyas city, $12.4 \%$ live in nearby villages and $8.3 \%$ live in the two neighbouring cities (Latakia and Tartus). (Shown in Figure 6)

\subsection{Statistical analysis and Chi square test}

The multiple-choice question (the current choice of transportation method when visiting the downtown area) shows that $26.2 \%$ of the participants chose to do their trip by walking, $21.5 \%$ are using public transportation, $20.9 \%$ are using their own car, $22.2 \%$ are using taxi, $7.4 \%$ are using motorbike and only $1.1 \%$ (6 participants) are currently cycling to the downtown area even though analysing the travel distance within the city found out that most of the trips are less than $3 \mathrm{~km}$ and it could be done by cycling. The reasons that prevent people cycling were statistically analysed throughout the survey sample and it was found that the two main reasons were the unavailability of proper infrastructure for cycling with a percentage of $40.1 \%$ and social reasons $23.7 \%$

There are other reasons that prevent people from cycling such as the difficulties of cycling in a slope area with $12.1 \%$, Health related reasons $8.2 \%$, cost of buying a bicycle $4.3 \%$, inability to ride a bicycle $3.9 \%$ and some other reasons which were described by some respondents with a percentage of $7.7 \%$ (Shown in Table 4)

Table 4. The reasons that prevent people from cycling

\begin{tabular}{lll}
\hline Reason & Frequency & Percentage \\
\hline Unavailability of proper cycling infrastructure & 225 & $40.1 \%$ \\
Social Reasons & 133 & $23.7 \%$ \\
I do not prefer to cycle in slope areas & 68 & $12.1 \%$ \\
Health related reasons & 46 & $8.2 \%$ \\
I cannot afford the cost of buying a bicycle & 24 & $4.3 \%$ \\
I do not know how to ride a bicycle & 22 & $3.9 \%$ \\
Other & 43 & $7.7 \%$ \\
\hline
\end{tabular}

Hypothesis testing _ As the previous part of the study focused on the mobility, the applicability of the non-motorized transport system and providing the necessary facilities for cycling and walking, the next part will focus on the social aspect through analysing its effect on the respondents based on their Gender and Age.

To take the characteristics of the society into consideration, the study discussed the four-following hypothesis and Chi square test was used to test the four hypotheses. The Chi Square statistic is commonly used for testing relationships between categorical variables. The null hypothesis of the Chi-Square test is that no relationship exists on the categorical variables; they are independent. And the alternative hypothesis is that there is a relationship between the variables. When $\mathrm{P}$ value is less than 0.05 the null hypothesis will be rejected. ${ }^{(24,25)}$

Hypothesis 1-1 There is a significant association between Age and inability to cycle due to social reasons.

The result: The Asymptotic significant or P value (significant value) $=0.010,0.010<$ the Alpha value $(0.05)$

Hypothesis 1-2 there is significant association between gender and inability to cycle due to social reasons

The result: The Asymptotic significant or P value (significant value) $<0.001,0.001<$ the Alpha value $(0.05)$

Hypothesis 2-1 There is a relationship between gender and the participant's acceptance to cycling after implementing the non-motorized proposal

The result: The Asymptotic significant or $\mathrm{P}$ value (significant value) $=0.38,0.38>$ the Alpha value $(0.05)$

Hypothesis 2-2 There is a relationship between age and the participant's acceptance to cycling after implementing the nonmotorized proposal

The result: The Asymptotic significant or $\mathrm{P}$ value (significant value) $<0.001,0.001<$ the Alpha value $(0.05)$ 


\subsection{Findings and Discussion}

According to the participants' answers, the social reasons could present an obstacle that prevents them from cycling. Therefore, within the previous part of the analysis, the focus was the social reasons that prevent people from cycling, we compared that factor with two main categories (Gender and Age groups). As a result of chi square analysis, there was a relationship between age and gender groups and the inability to cycle due to social reasons. It was noticeable that older people were more affected by social reasons than the younger generation and same for females as they were more affected than males.

Participants were obviously affected by social aspects based on their age, and it was noticeable that the data of age groups are divided into two groups with two different directions of being affected by the social reasons. The first group includes the two younger groups under 18 and between 18 and 23, these two groups showed a high percentage of being not affected by social reasons, the second group includes the three other older ages and the answers of the people in these three groups showed a balance between being affected and not affected by social reasons. In other words, people under 24 years old were less affected by the social aspect as a reason to prevent them from cycling. (Shown in Figure 7)

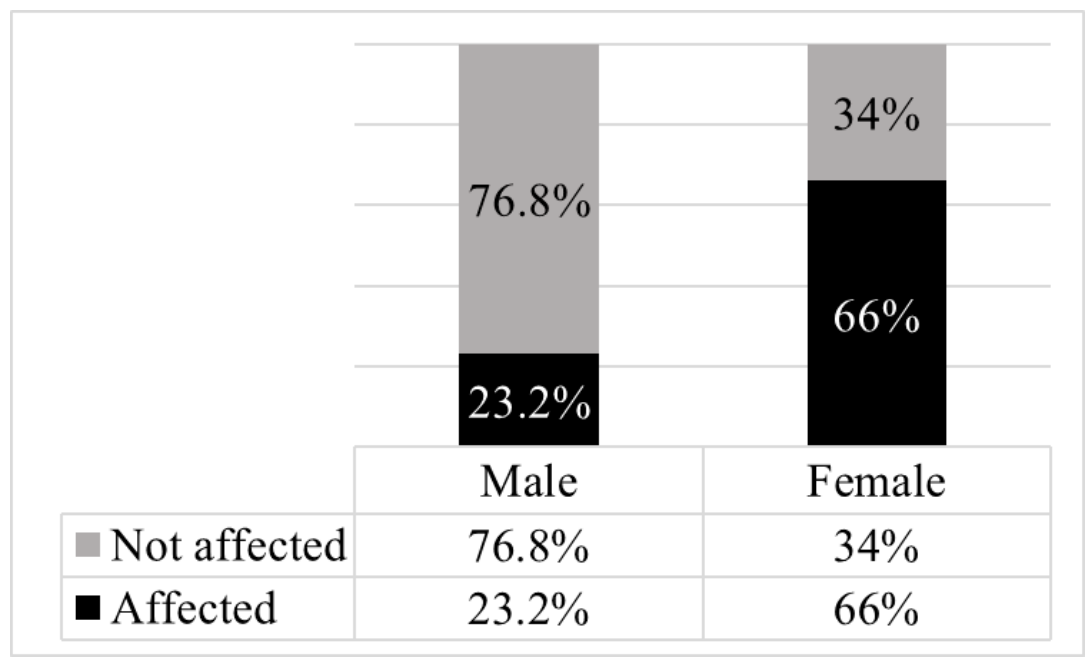

Fig 7. Age and social reasons, Percentage

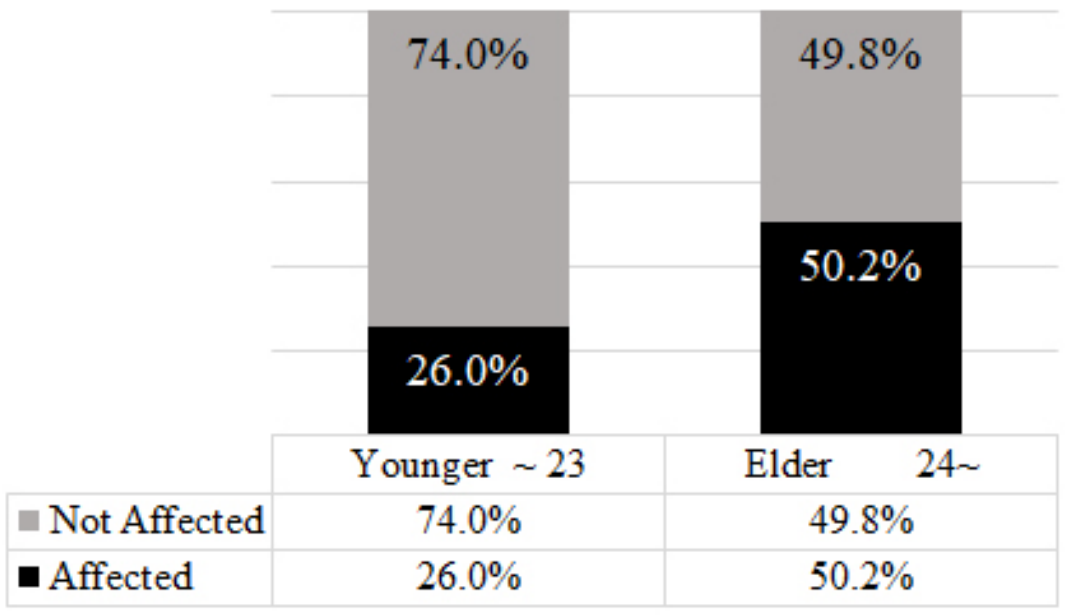

Fig 8. Gender and social reasons, Percentage

And the participants were also affected based on their gender, 97 out of 147 (66\%) of the female participants were affected by social reasons while only 35 out of 151 (23.2\%) of male participants answered positively to being affected by social reasons, 
in other words women are more affected by a social reason as an obstacle that prevents them from cycling. (Shown in Figure 8)

And when giving people the chance to cycle in better conditions (after implementing the pedestrianization proposal), the gender did not have any effect on the desire to cycle, in other words women also were willing to cycle as much as men. In the comparison chart, we can see that female and male both showed almost the same level on acceptance to cycling, while the negative opinion showed a little difference $(21.9 \%=33$ out of 151 males were not willing to cycle, while $16.3 \%-24$ out of 147 females did not agree to cycle). (Shown in Figure 9)

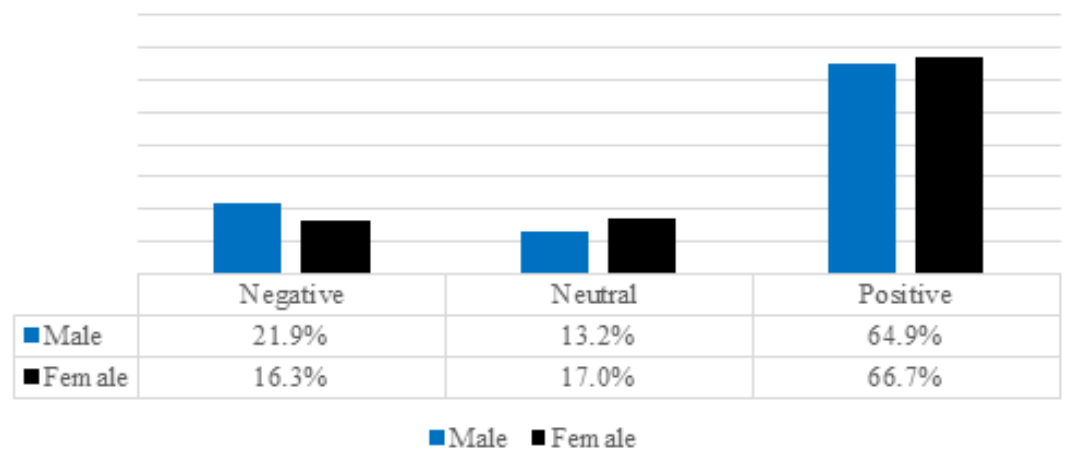

Fig 9. A comparison between the desire to cycle after implementing the proposal and Gender, Percentage

But the age was still a significant factor in people's desire to cycle, it was noticeable that opinions of older people (over 36 years old were generally neutral towards cycling) while younger people showed a high level of acceptance to cycling, a noticeable change in the distribution of these age groups appeared, and the younger generation (under 36 years old) showed a high level of approval to cycling. According to it, the data was divided into two age groups The first group includes the three younger groups under 36 years old, these groups showed a high level of acceptance to cycling, the second group includes the two other older ages and the answers of the people in these two groups showed a balance or disagreement to the idea of cycling. (Shown in Figure 10)

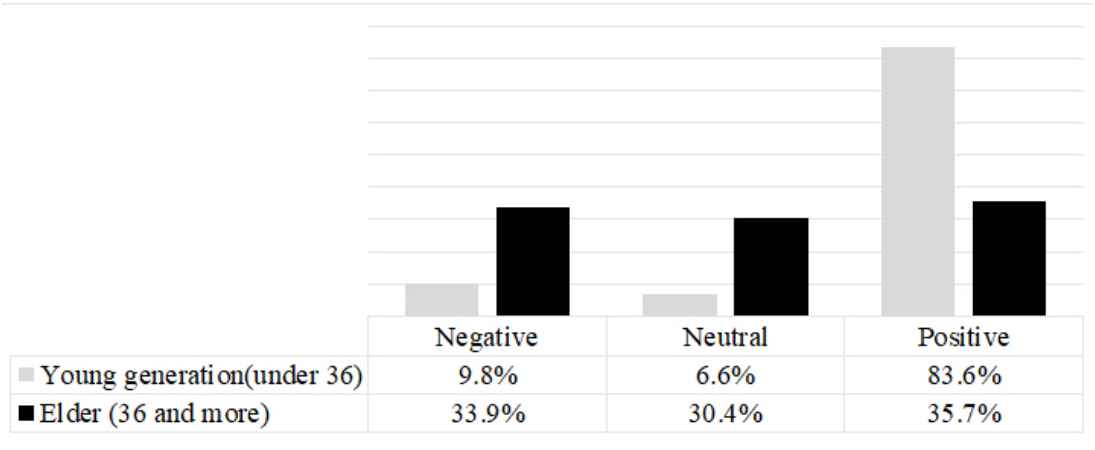

Fig 10. A Comparison of the desire to cycle after implementing the proposal and Age Groups-Percentage

\subsection{Analysing the ideas and suggestions of the participants}

At the end of the questionnaire the participants were asked to write down their suggestions to improve the proposed plan, within 298 valid participants 37 participants shared one or more idea and suggestion to improve the proposal, the KJ-Method was applied to analyse the responses. The KJ-Method or KJ Technique, is an idea generating and prioritizing technique named after its inventor, the Japanese ethnologist Jiro Kawakita. This technique is one of the most popular brainstorming variations for design, team, retrospective, and project meetings. The method was applied starting by writing down the rough ideas, organizing them in main groups and subgroups based on their concept. The interactions and similar points between suggestions were registered as focus points while taking some unique ideas into consideration. ${ }^{(26,27)}$ The suggestions of the participants fall in to five main groups (Related to cycling, related to vehicle parking and traffic laws, related to businesses and markets, related to 
public transportation, and related to public health) and the opinions of within each group were divided into different subgroups as shown in the Figures 11 and 12.

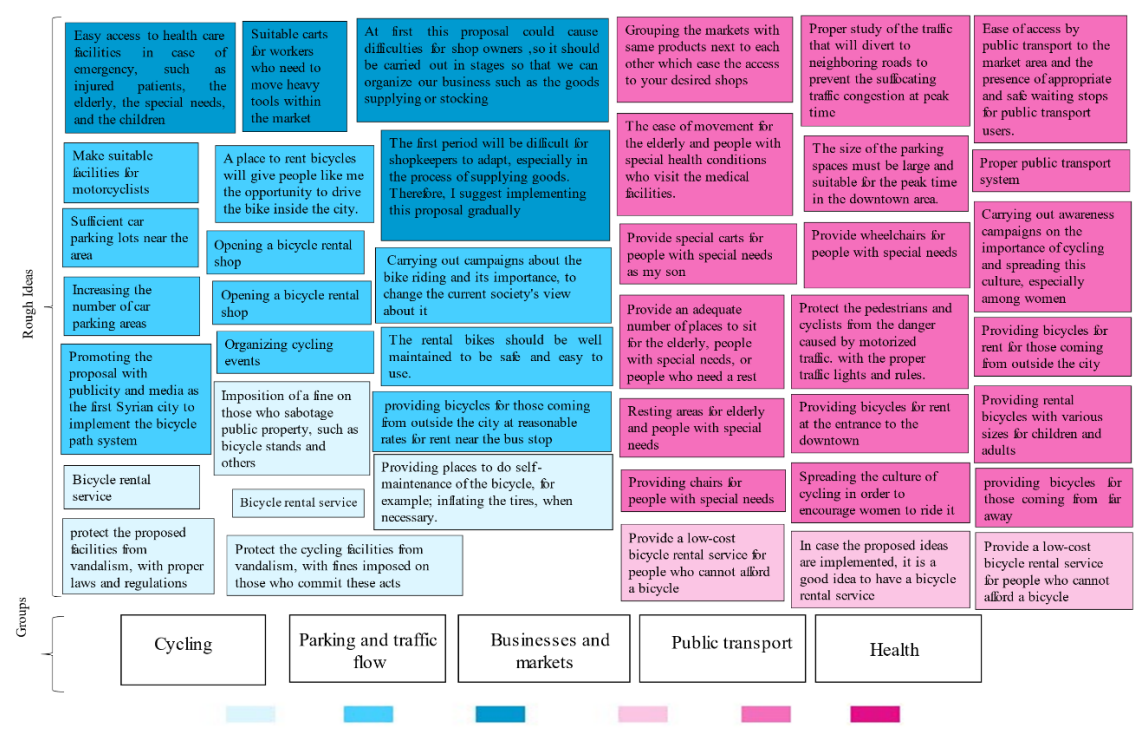

Fig 11. Rough Ideas and main groups

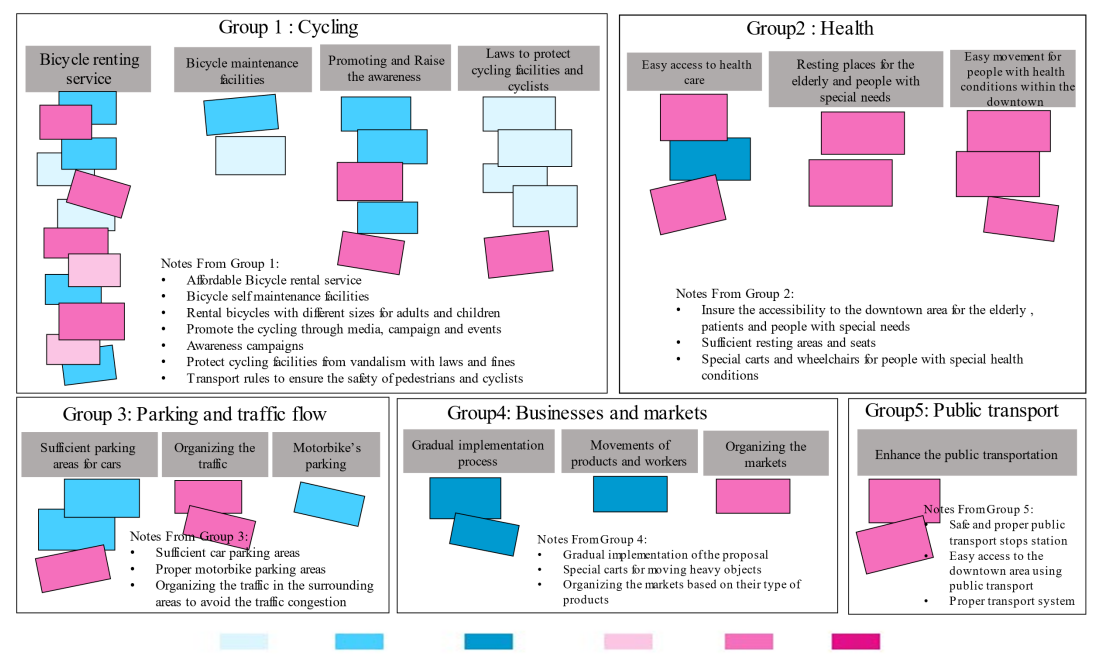

Fig 12. Distributing the ideas within the subgroups

\section{Concerns of the participants}

- Unavailability of bicycles and bicycle maintenance facilities

- Lack of public acceptance and understanding to the culture of cycling

- Unsafe situation for cyclists and pedestrians 
- Difficulties related to the access to the health care facilities

- Difficulties for people with health conditions such as people with special needs and the elderly

- Insufficient car and motorbikes parking facilities

- Unavailability of public transport system

- Difficulties related to the process of goods supplement for the stores

\section{Concluded ideas and suggestions}

- Affordable bicycle rental service with different sizes for adults and children

- Bicycle self-maintenance facilities

- Promote the cycling idea through media, campaign, and events

- Awareness campaigns

- Protect cycling facilities from vandalism with laws and fines

- Transport rules to ensure the safety of pedestrians and cyclists

- Insure the accessibility to the downtown area for the elderly, patients, and people with special needs

- Sufficient resting areas and seats

- Special carts and wheelchairs for people with special health conditions

- Sufficient car parking areas

- Proper motorbike parking areas

- Organizing the traffic in the surrounding areas to avoid the traffic congestion

- Gradual implementation of the plan

- Special carts for moving heavy objects

- Organizing the markets based on their type of products

- Safe and proper public transport stops

- Easy access to the downtown area using public transport

\section{Conclusion}

As the issues related to motorized traffic was found to cause too many difficulties in the downtown area, the proposal of the nonmotorized transport system was presented to the people through an online questionnaire using media with-image explanation method, the participants were able to understand the proposed plan and answer it while actively participating with their ideas and suggestions. Besides the unavailability of proper cycling facilities, social reasons were found to be one of the main issues that control people's ability to ride a bicycle. The impact of the social reasons varied between participants according to their age and gender. And it was noticeable that women were more affected by the social aspects and the older groups of people (over 24 years old) were also affected by them. And when giving the participants the choice to cycle under better conditions after implementing the proposal, it was noticeable that the females were as motivated to ride a bicycle as males.

By taking the results and the participants' suggestions into account, the non-motorized system can be applied and improved based on the understanding to the situation of the area and the special requirements accrued by the nature of society, the study gives a ground floor to improve the transport system in the downtown area while covering the uniqueness of the social aspect. A further study is recommended to create the practical steps to implement the proposed system.

\section{References}

1) Beatly T. Green Urbanism: Learning from European cities. Landscape and Urban Planning. 2000;51(1):64-65. doi:10.1016/S0169-2046(00)00074-8.

2) Tsubohara S. Democracy through political parties and public participation: the case of the planning history of Groningen, The Netherlands. 2010. Available from: https://research.rug.nl/en/publications/democracy-through-political-parties-and-public-participation-the-.

3) Tsubohara S. The effect and modification of the Traffic Circulation Plan (VCP) - traffic plannign in Groningen in the 1980s. 2007. Available from: https://research.rug.nl/en/publications/the-effect-and-modification- of-the-traffic-circulation-plan-vcp-t.

4) Reclaiming city streets for people Chaos or quality of life. EUROPEAN COMMISSION Directorate-General for the Environment, 52 p. 2015. .

5) Suzuki H, Cervero R, Iuchi K. Transforming cities with transit, Transit and Land-use integration for sustainable urban development. Washington, DC. The World Bank. 2013. Available from: https://openknowledge.worldbank.org/handle/10986/12233.

6) Soni N, Soni N. Benefits of pedestrianization and warrants to pedestrianize an area. Land Use Policy. 2016;57:139-150. Available from: https: //doi.org/10.1016/j.landusepol.2016.05.009.

7) Uzunoğlu K, Uzunoğlu SS. The Importance of Pedestrianization in CitiesAssessment of Pedestrianized Streets in Nicosia Walled, Wong RC. European Journal of Sustainable Development. 2020;9(2):589-614. Available from: https://doi.org/10.14207/ejsd.2020.v9n2p589.

8) Wang Y, Chau CK, Ng WY, Leung TM. A review on the effects of physical built environment attributes on enhancing walking and cycling activity levels within residential neighbourhoods. Cities. 2016;50:1-15. Available from: https://doi.org/10.1016/j.cities.2015.08.004.

9) UN Demographic Yearbook, Central Bureau of Statistics, Syrian Arab Republic. 2011. 
10) The Syrian statistic centre, Tartus Province, Census of 2018.

11) The transportation department of Tartus province, transportation report of Baniyas area 2014 and 2017.

12) Baniyas city office, Department of City planning, Land use study, 2010. .

13) Freydig M, César H. Design of Non-Motorized Mobility plan for Warm Climate Cities, Case: Hermosillo, Sonora, Mexico. San Luis Potosi, Mexico. 2016. Available from: https://ninive.uaslp.mx/xmlui/handle/i/4672.

14) Uzunoğlu SS, Uzunoğlu K. Accessibility of the old cities for the Blind-Is Nicosia walled city accessible for the blind? International Journal of Advanced and Applied Sciences;7(10):86-94. Available from: https://doi.org/10.21833/ijaas.2020.10.009.

15) Yassin H. Liveable city: An approach to pedestrianization through tactical urbanism. Alexandria Engineering Journal. 2019;58(1):251-259. Available from: https://doi.org/10.1016/j.aej.2019.02.005.

16) Zacharias J. Pedestrian Behavior Pedestrian Behavior and Perception in Urban Walking Environments. Journal of Planning Literature. 2001;16(1):3-18. doi:10.1177/08854120122093249.

17) The Syrian Centre of Weather and Climate, weather report of Baniyas area, 2016.

18) Talpur MAH, Napiah M, Chandio I, Khahro SH. Transportation Planning Survey Methodologies for the Proposed Study of Physical and Socio-economic Development of Deprived Rural Regions: A Review. Modern Applied Science. 2012;6(7):1-16. doi:10.5539/mas.v6n7pl.

19) Richardson AJ, Ampt ES, Meyburg AH. Survey Methods for Transport Planning. Oakland. Eucalyptus Press. 1995.

20) Thillaiampalam S, Okamura T, Nkamura F. A Systematic approach for Questionnaire Design of New Transit System Implementation in Developing Countries. Proceedings of the Eastern Asia Society for Transportation Studies. 2007;6:1664-1679. doi:10.11175/easts.7.1664.

21) Guidance for Pre- and Post-test Design, EMpowerempowerweb.org.

22) Aminu SA, Pearse OE. Transportation Externalities Reduction and Ridership of Bus Rapid Transit (BRT) in Lagos Metropolis. Journal of Sustainable Development in Africa. 2018;20(1):211-231. Available from: https://jsd-africa.com/Jsda/Vol20No1\%20Spring\%202018/2\%20EnvironmentalInfrastructureLand-Use/Transportation\%20Externalities\%20Reduction\%20and\%20Ridership_Suraju\%20\%20Aminu.pdf.

23) Cronbach LJ. Coefficient alpha and the internal structure of tests. Psychometrika. 1951;16:297-334. Available from: https://link.springer.com/article/10. 1007/BF02310555.

24) Rana R, Singhal R. Chi-square test and its application in hypothesis testing. Journal of the Practice of Cardiovascular Sciences. 2015;1:69-71. doi:10.4103/2395-5414.157577.

25) Franke TM, Ho T, Christie CA. The Chi-Square Test: Often Used and More Often Misinterpreted. American Journal of Evaluation. 2011;33(3):448-458. Available from: https://doi.org/10.1177/1098214011426594.

26) Scupin R. The KJ Method: A Technique for Analyzing Data Derived from Japanese Ethnology. Human Organization. 1997;56(2):233-237. doi:10.17730/humo.56.2.x335923511444655.

27) Iba T, Yoshikawa A, Munakata K, PLoP '17: Pattern Languages of Programs Conference Vancouver. Philosophy and methodology of clustering in pattern mining: Japanese anthropologist Jiro Kawakita’s KJ method.. 2017;p. 1-11. Available from: https://dl.acm.org/doi/abs/10.5555/3290281.3290296. 